\title{
Studying the Steady State Performance Characteristics of Induction Motor with Field Oriented Control Comparing to Scalar Control
}

\author{
Hamdy Mohamed Soliman
}

\begin{abstract}
Field oriented control is from the best methods to control the AC drives this is because this method of control transfers the advantages of DC drives into AC drives. With using this method of control, the torque per ampere for $\mathrm{AC}$ machines increases, the dynamic performance becomes higher, transient and steady state performance become improvement. This paper is comparing between the steady state characteristics of induction motor with using the field oriented control and scalar control to show the advantages of the field oriented control comparing to scalar control. this studying not only concerned with constant flux region but also focused in the field weakening region. The MATLAB program is used to studying the steady state performance characteristics of induction motor with field oriented control and scalar control.
\end{abstract}

Index Terms - Field oriented control, Induction motor, Scalar control.

\section{INTRODUCTION}

Induction motor is preferable in industrial applications due to have many advantages as low cost, low maintenance, high operating life, self-starting and can be used in enclosed area such as mines. Induction motor can be operated under effect of many methods of controls such as scalar control and field oriented control. in the scalar control, the induction motor can be controlled in open loop and closed loop controls [1-4]. The open loop control is preferable when high dynamic performance isn't required. In open loop control at constant flux region, the applied voltage on the motor (induction motor) is in portion with frequency (as magnitude only) to keep the flux inside the machine constant to get the rated torque but in the field weakening region, the voltage is kept constant and frequency increases to get speeds behind the rated speed and the load torque is inversely proportional these speeds. In the field weakening region, voltage reaches rated value so this volt doesn't increase due to not burn the stator winding. In field oriented control, the voltage and frequency can be controlled in the two regions (constant flux region and field weakening region) as in the scalar control but the voltage is applied as the vector in the space [5-7]. This paper is used to comparing between the steady state performance characteristics of induction motor with using field oriented control and with using the scalar control in the constant flux region and in the field weakening region to show the

Manuscript published August 31, 2016.

Hamdy Mohamed Soliman, The development and researcher director in Cairo Merto Gereater, Helwan, Egypt.

(e-mail: hamdysoliman123@gmail.com). advantages the field oriented control if it is compared to the scalar control. In this study, the run-up characteristics and the load characteristics are compared. This study is made by MATLAB program. This paper is divided as the follows; IIntroduction, II- Scalar control of induction motor, III- The oriented control, IV-Simulation result, V- Conclusions.

\section{SCALAR CONTROL OF INDUCTION Motor}

The operating of the scalar control for induction motor can be represented as Fig.1. the operating regions can be classified into:

1- Constant flux region

\section{2- Constant power region}

In the constant flux region, the voltage is applied on the motor is in portion with frequency to make the motor flux is constant as the same value of rated flux to keep the motor torque at rated. The most common problem in this region is at low frequency where the voltage drop at the stator resistance cannot be neglected because the motor becomes under excited i.e. the motor flux is reduced about the rated value. To solve this problem, the voltage drops across the stator resistance must compensated.

In constant power region, the voltage is kept constant at rated value and frequency increases to get higher speed for operating region. In this region, the motor voltage doesn't increase because this is harmful for the stator windings i.e. they are designed so as not to exceed the rated value of the voltage. also when they are operated in this region by same criteria of the above region, the motor becomes saturated. Also in this region, due to the voltage doesn't increase and frequency increases, the motor torque is inversely proportional to motor speed.

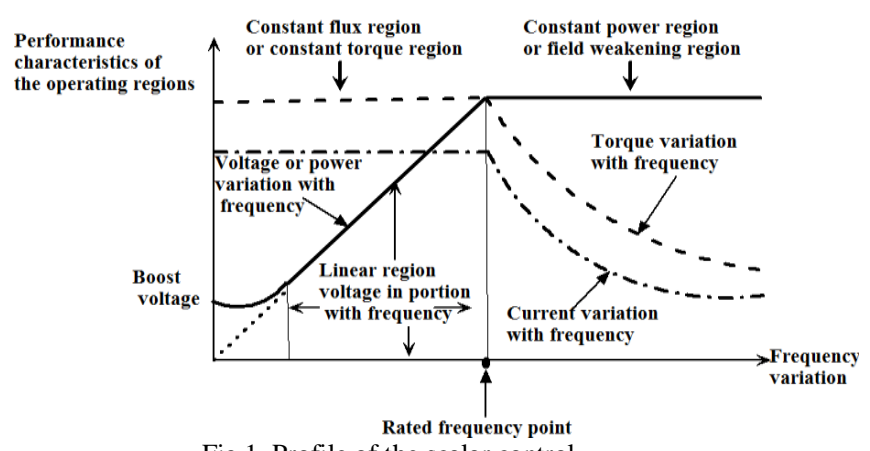

Fig 1. Profile of the scalar control

The following equations represent the mathematical model of the induction motor at steady state for the stationery reference frame. 


$$
\begin{gathered}
V_{s}=\left(R_{s}+J \omega_{e} L_{s}\right) I_{s}+J \omega_{e} L_{m} I_{r} \\
0=\left(\frac{R_{r}}{S}+J \omega_{e} L_{r}\right) I_{r}+J \omega_{e} L_{m} I_{s}
\end{gathered}
$$

With help of voltage Eqs. (1-2) the stator current can be represented as

$$
\begin{aligned}
I_{s} & =\frac{V_{s}}{\left(R_{s}+\frac{\left(\omega_{e} L_{m}{ }^{2} \frac{R_{r}}{s}\right.}{\left(\frac{R_{r}}{s}\right)^{2}+\left(\omega_{e} L_{r}\right)^{2}}\right)+J\left(\frac{\left.R_{r}\right)^{2} L_{s}+\omega_{e}{ }^{2}\left(L_{s} L_{r}{ }^{2}-L_{r} L_{m}{ }^{2}\right)}{\left(\frac{R_{r}}{s}\right)^{2}+\left(\omega_{e} L_{r}\right)^{2}}\right)} \\
I_{r} & =-\frac{{ }^{2} \omega_{e} L_{m} I_{s}}{\left(\frac{R_{r}}{S}+J \omega_{e} L_{r}\right)} \\
T_{e} & =\frac{3}{4} P\left(\frac{R_{r}}{\left(\frac{R_{r} L_{s}}{s}\right)^{2}+\omega_{e}{ }^{2}\left(L_{m}{ }^{2}-L_{s}{ }^{2} L_{r}\right)^{2}}\right)
\end{aligned}
$$

Where $L_{s}=L_{m}+L l_{s}, L_{r}=L_{m}+L l_{r}$

$$
P_{0}=T_{e} \omega_{m}
$$

$$
P_{\text {losses }}=3\left(R_{s} I_{s}{ }^{2}+R_{r} I_{r}{ }^{2}\right)
$$

$P_{\text {in }}=P_{0}+P_{\text {losses }}$

$\eta=\frac{P_{0}}{P_{\text {in }}} X 100$

Where $V_{s}$ is the stator voltages, $I_{s}, I_{r}$ are the stator and rotor currents, $L_{s}, L_{m}, L_{r}$ are the stator, magnetizing and rotor inductances, $L l_{r}, L l_{r}$ are the leakage inductances for stator and rotor, $R_{s}, R_{r}$ are the stator and rotor resistances $T_{e}$ is a developed torque, is the $\omega_{m}$ mechanical motor speed, $\omega_{e}$ is electrical frequency in rad, $\mathrm{S}$ is the slip, $P_{0}$ is the output power, $P_{\text {losses }}$ is the power losses, $P_{\text {in }}$ is the input power, $P$ is the number of poles and $\eta$ is the efficiency.

From Eqs. (1-2) the induction motor model in the stationery reference frame can be represented as in Fig.2.

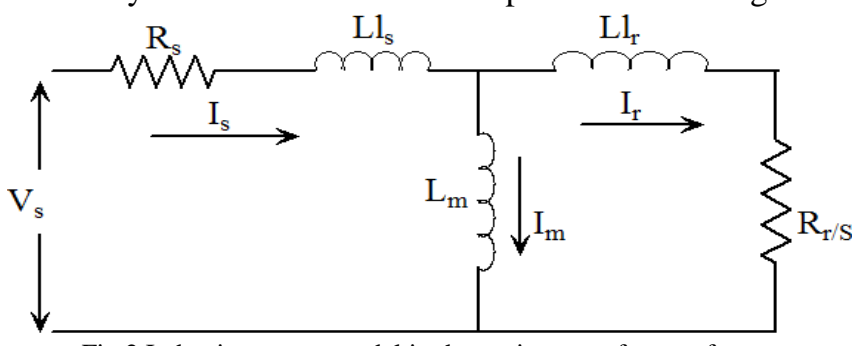

Fig.2 Induction motor model in the stationery reference frame

\section{THE FIELD ORIENTED CONTROL}

The field oriented control (FOC) makes the induction motor emulates the separately excited DC motor. To understand this let's start with the principle torque equation:

$$
\mathrm{T}_{\mathrm{e}}^{\alpha} \psi_{\mathrm{s}} \psi_{\mathrm{r}} \sin \mathcal{E} \cos \Gamma
$$

Where $\psi_{\mathrm{s}}$ and $\psi_{\mathrm{r}}$ are stator and rotor flux linkages, $\varepsilon$ and $\Gamma$ are the space and time angles between stator and rotor flux linkages.

If it is applied on DC machine it is found that,

The space angle is equal to $90^{\circ}$ and time angle is $0^{\circ}$ because the field comes from DC field hence the torque equation becomes as the follows

$\mathrm{T}_{\mathrm{e}}^{\alpha} \psi_{\mathrm{s}} \psi_{\mathrm{r}}$

So the torque becomes maximum value. By applying this equation on induction motor, it found that, the space angle is smaller than $90^{\circ}$. Hence, to verify the same torque taken from DC, the rotor or stator flux must be increased, by such an increase in the stator current and hence it found that, the torque per ampere of $\mathrm{DC}$ is higher than the torque per ampere of induction motor.

By applying the FOC it is found that, the torque problem is solved this is because the space angle between rotor flux and stator flux becomes $90^{\circ}$. Fig. 3 shows the DC and induction motor space angle where it is found that,

DC motor has constant space angle $90^{\circ}$ but induction motor has varying one which increases by increasing the load, it reaches $90^{\circ}$ at maximum load because the induction motor is coupling machine.

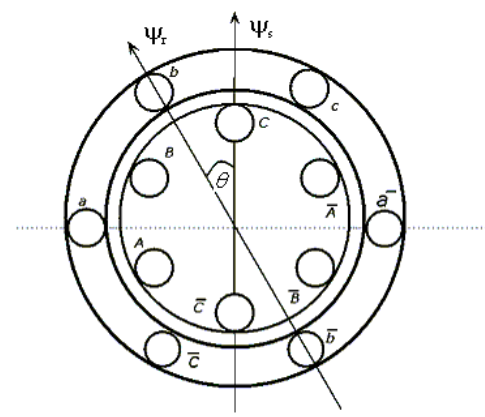

(a) Space angle between rotor and stator fluxes of induction motor

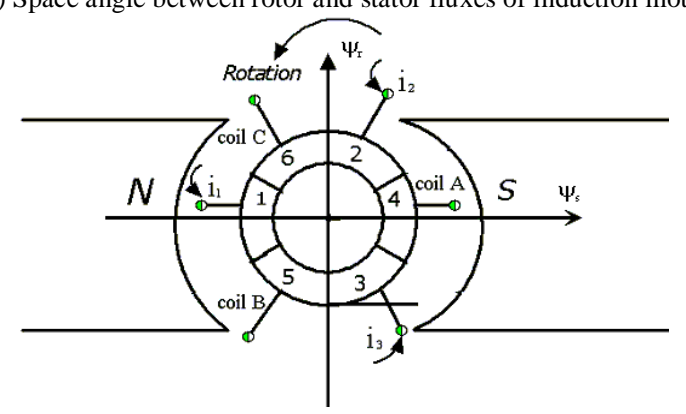

(b) Space angle between armature and field flux of DC motor

Fig. 3 Space angle for DC motor and induction motor between rotor and stator flux 
When comparing between the armature current for both of DC motor and induction motor it found that, the armature current of DC motor is smaller at low loads and increases linearly by increasing the load where in induction motor, the current becomes higher at low loads and increased by higher values by increasing the load as shown in the Fig. 4 and this shows that, the torque per ampere of DC motor is higher than the torque per ampere of induction motor case, hence there are many models to improve the torque per ampere in induction motor by making the space angle between rotor and stator field is always $90^{\circ}$ at any load and speed of the motor. This control is called FOC which leads to a decrease in the stator current and an increase in the efficiency and output power. By applying FOC on the induction motor, input current can be decoupled into flux and torque current components [8-10]. Hence the induction motor with this control becomes good fast dynamic performance and good transient response, this is the objective from applying the FOC which implements

$90^{\circ}$ space angle between rotor and stator fluxes. By this way the induction motor emulates DC motor i.e. By applying the FOC it could be controlled in the stator magnetic-field vector, which is a vector with two components, magnitude and phase angle. Where by assuming that, the angle between rotor and stator field vectors is $(\varepsilon)$. It affects the torque according to:

$$
\mathrm{T}_{\mathrm{e}}=\mathrm{T}_{\max } \sin \varepsilon
$$

At $\varepsilon=0^{\circ}$,

The fields are in equilibrium and no torque is produced

but when two fields are perpendicular $\varepsilon=90^{\circ}$ the maximum torque is occurring and this is the goal from applying the FOC.

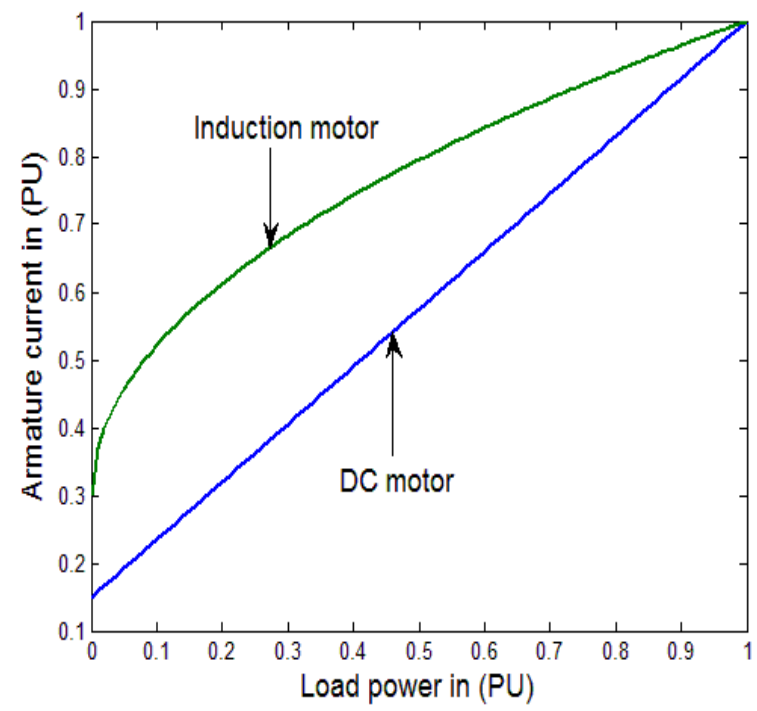

Fig.4 Variation of armature current with load power in case of induction motor and DC motor

The following equations represent the mathematical model of the induction motor at steady state for FOC

$$
\mathrm{V}_{\mathrm{ds}}=\mathrm{R}_{\mathrm{s}} \mathrm{I}_{\mathrm{ds}}-\omega_{e} \mathrm{~L}_{\mathrm{s}} \mathrm{I}_{\mathrm{qs}}-\omega_{e} \mathrm{~L}_{\mathrm{m}} \mathrm{I}_{\mathrm{qr}}
$$

$$
\begin{aligned}
& \mathrm{V}_{\mathrm{qs}}=\mathrm{R}_{\mathrm{s}} \mathrm{I}_{\mathrm{qs}}+\omega_{e} \mathrm{~L}_{\mathrm{s}} \mathrm{I}_{\mathrm{ds}} \\
& 0=S \omega_{e} \mathrm{~L}_{\mathrm{m}} \mathrm{I}_{\mathrm{qs}}-S \omega_{e} \mathrm{~L}_{\mathrm{r}} \mathrm{I}_{\mathrm{qr}} \\
& 0=R_{r} \mathrm{I}_{\mathrm{qr}}+S \omega_{e} \mathrm{~L}_{\mathrm{m}} \mathrm{I}_{\mathrm{ds}} \\
& T_{e}=\frac{3}{4} P \frac{L_{m}}{L_{r}} \psi_{r} I_{q s} \\
& P_{0}=T_{e} \omega_{m} \\
& \left.P_{\text {in }}=\frac{3}{2} V_{d s} I_{d s}+V_{q s} I_{q s}\right) \\
& P_{\text {losses }}=P_{\text {in }}-P_{0}
\end{aligned}
$$

Where $V_{d s}, V_{q s}$ are the dq axes stator voltages, $I_{d s}, I_{q s}$ are the dq axes stator currents, and $I_{q r}$ is the q axes rotor current.

\section{Simulation Results}

The simulation results of the scalar control and FOC is discussed here for induction motor which has motor data in appendix 1. This simulation is compared to steady state scalar control method to steady state FOC method to show the effectiveness of the FOC method. The simulation concluded three cases arranged as the follows;

1- The comparing between the run-up characteristics of induction motor in case of scalar control and FOC.

2- The comparing between the load characteristics of induction motor in case of scalar control and FOC.

3- The comparing between the operating characteristics of induction motor in constant flux region and the constant power region in case of scalar control and FOC.

\section{A. First Case of Study}

In this case; the run-up characteristics of induction motor are studied with scalar control and with the FOC. The runup studied through three cases. These cases are

1- The Performance characteristics of induction motor with constant parameters.

2- The Performance characteristics of induction motor with taking into consideration of the skin effect on the rotor parameters are shown in Fig. 5.

3- The Performance characteristics of induction motor with taking into consideration the effect of temperature raise on the motor parameters are shown in Fig. 6.

The rotor parameters in the $2^{\text {nd }}$ case are computed by using the knowledge of name plat and data sheet of the motor. This data is introduced into MATLAB program for concluding the curves shown in Fig. 5. In the $3^{\text {rd }}$ case, Fig. 6 shows the effect of temperature raise on the rotor and stator resistances. In all Figs. Conventional means scalar control and oriented means FOC 


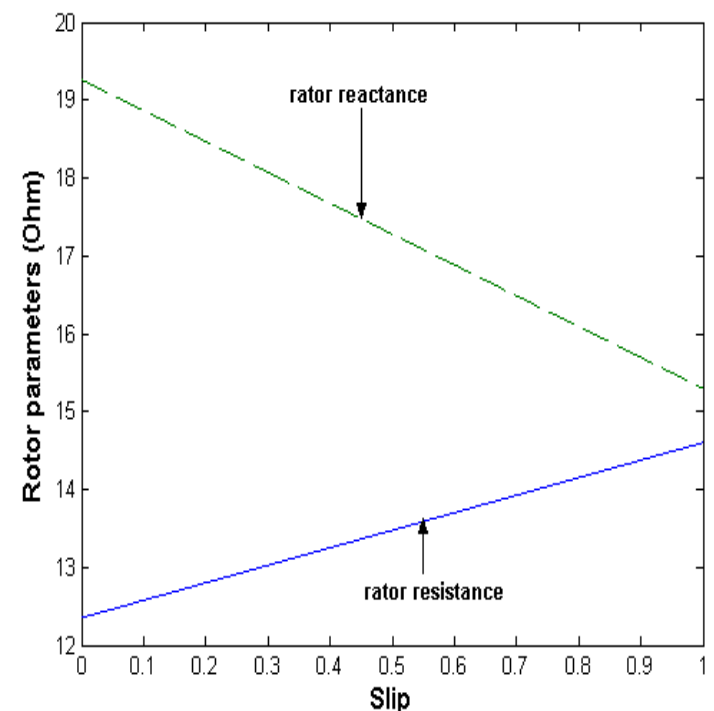

Fig.5 Variation of rotor parameters with slip taken into account the skin effect

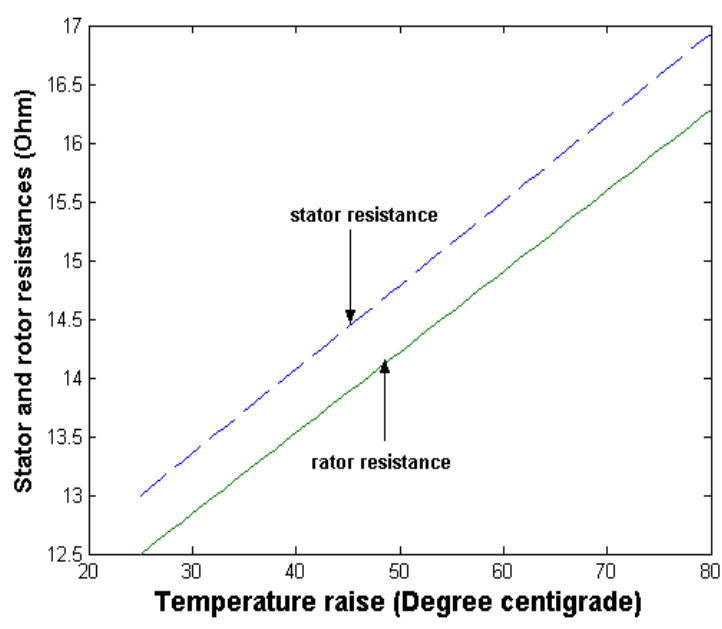

Fig.6 Effect of temperature on stator and rotor resistances

Fig.7 shows the improvement in the motor torque in all cases of study with FOC comparing to scalar control this because the stator flux and rotor flux becomes orthogonally.

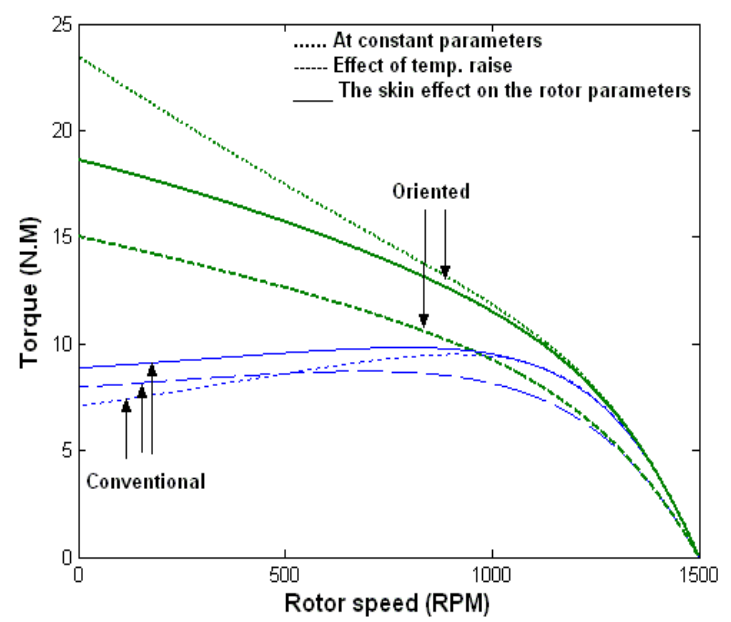

Fig.7 Variation of torque with rotor speed

The stator current with conventional method and with FOC can be seen in Fig. 8 Where from these Figs. It is found that; The stator current is smaller with the FOC.

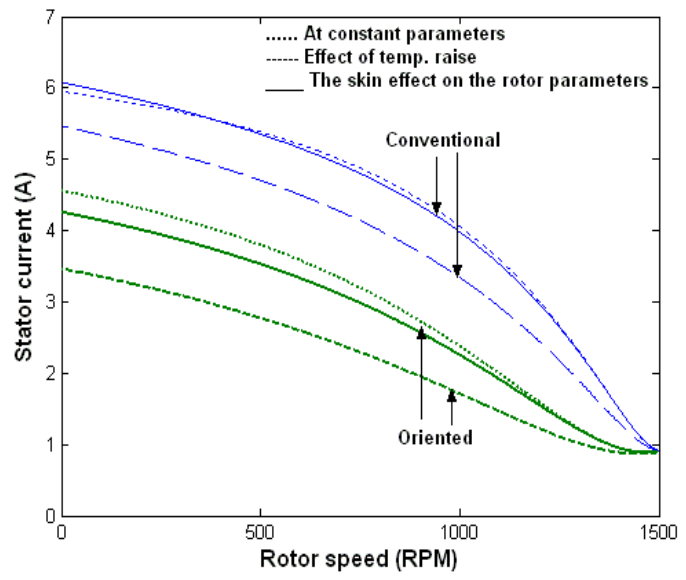

Fig.8 Variation of stator current with rotor speed

Due to increase of the motor torque with FOC, the output power increases with FOC comparing to conventional method as shown in Fig. 9.

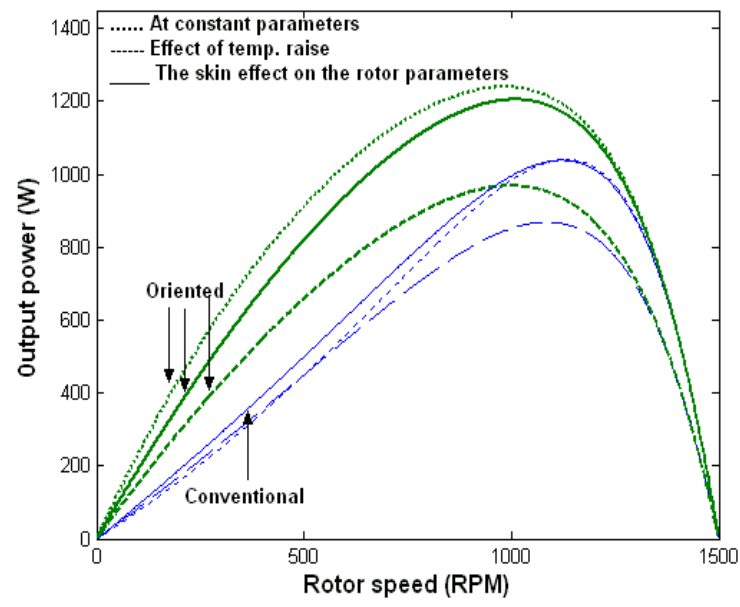

Fig.9 Variation of output power with rotor speed

Due to decrease of the stator current with FOC, the input power and power losses decrease with FOC comparing to conventional method as shown in Fig. 10 and Fig. 11 respectively.

Due to increase in the output power and a decrease in the power losses with FOC, the efficiency increases with FOC comparing to the efficiency with conventional method as shown in Fig. 12.

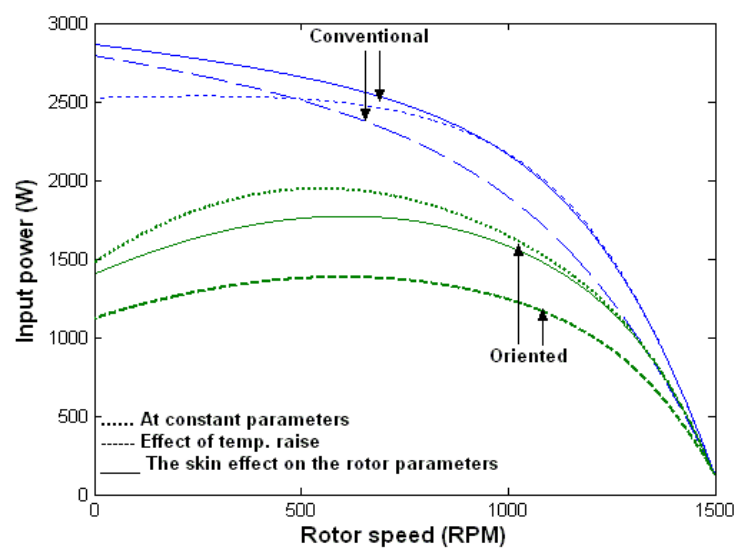

Fig. 10 Variation of input power with rotor speed 


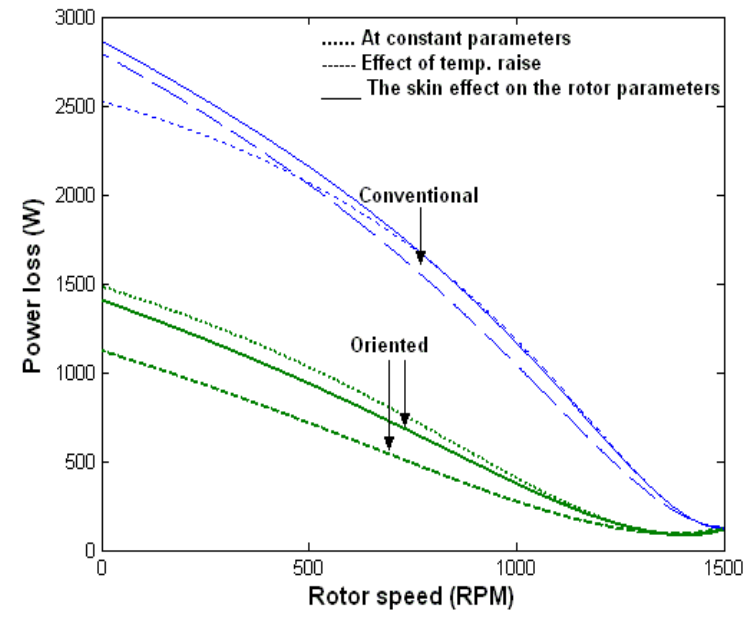

Fig. 11 Variation of power loss with rotor speed

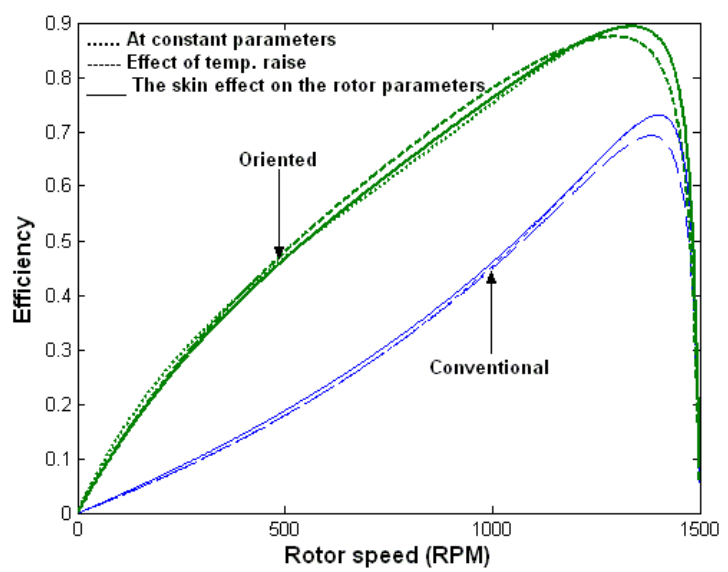

Fig. 12 Variation of efficiency with rotor speed

\section{B. Second Case of Study}

The load characteristics for induction motor with FOC (oriented) and with scalar control (conventional) are compared here where from simulation it is found that;

Fig.13 shows the variation of the motor speed with variation of the load torque where it is found that; the motor speed with FOC is higher than that with conventional method at the same torque this because with the FOC, the induction motor is working at small slip.

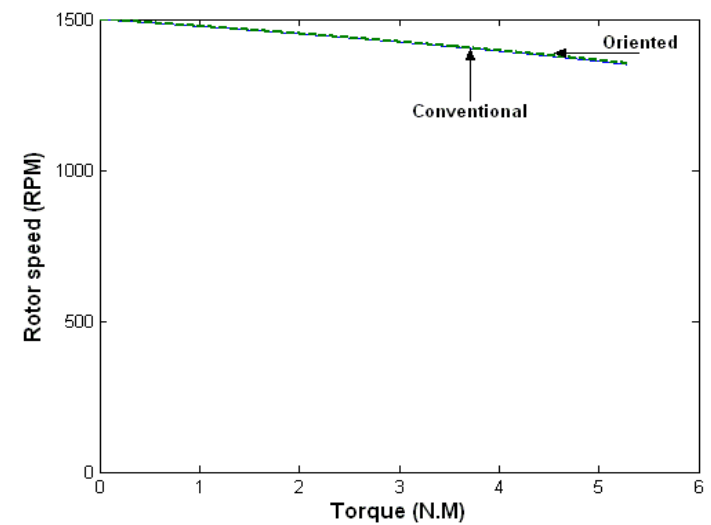

Fig. 13 Variation of torque with rotor speed The stator current with conventional method and with FOC can be seen in Fig. 14 Where from this

Fig. It is found that; The stator current is smaller with the FOC.

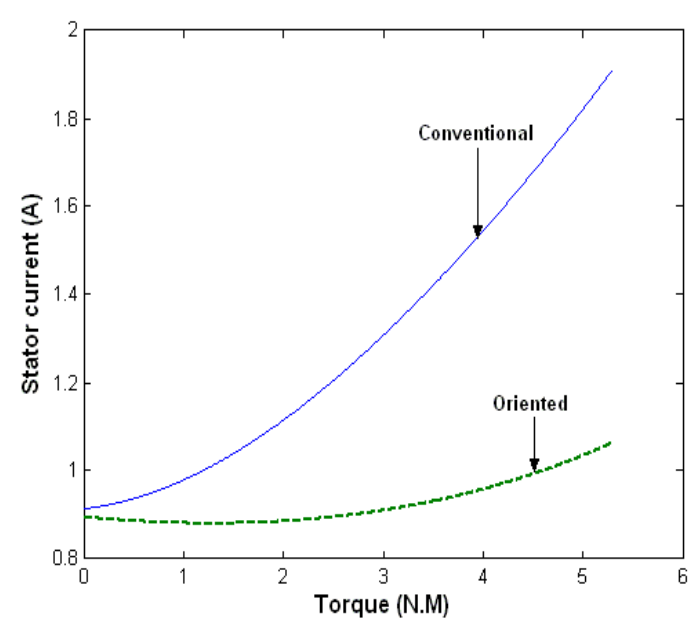

Fig. 14 Variation of stator current with rotor speed

Due to increase of the motor speed with FOC, the output power increases with FOC comparing to conventional method as shown in Fig. 15.

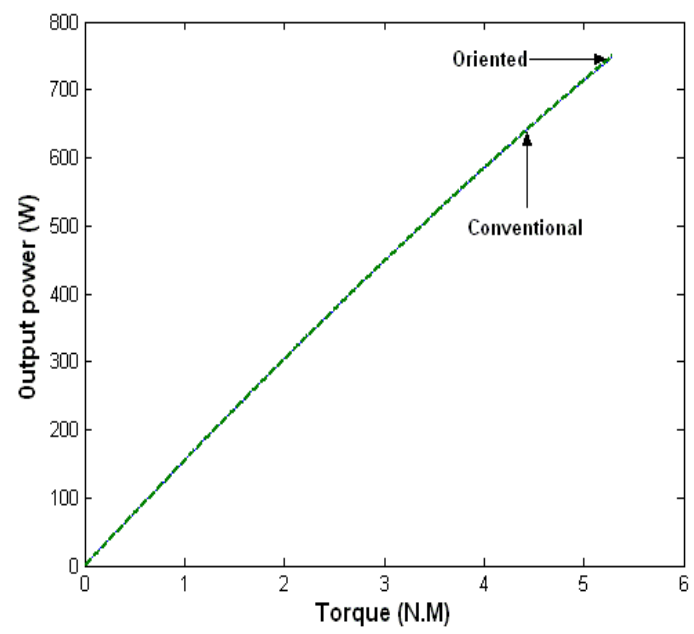

Fig. 15 Variation of output power with rotor speed

Due to decrease of the stator current with FOC, the input power and power losses decrease with FOC comparing to conventional method as shown in Fig. 16 and Fig. 17 respectively.

Due to increase in the output power and a decrease in the power losses with FOC, the efficiency increases with FOC comparing to the efficiency with conventional method as shown in Fig. 18. 


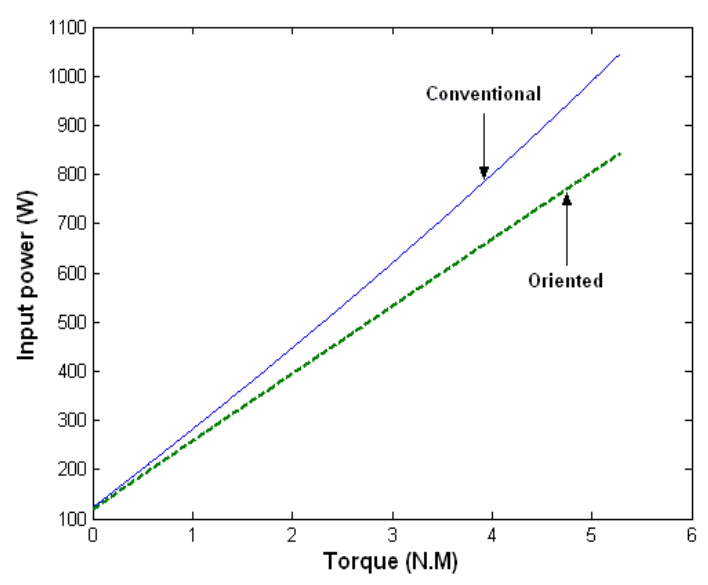

Fig. 16 Variation of input power with rotor speed

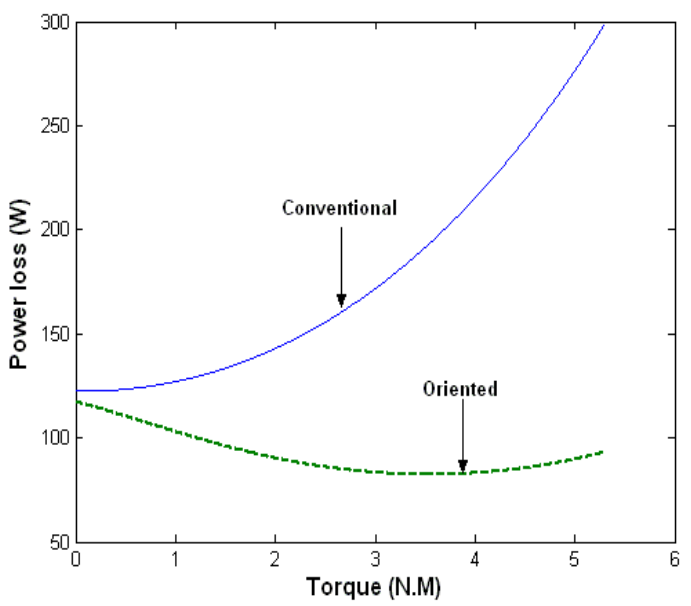

Fig. 17 Variation of power loss with rotor speed

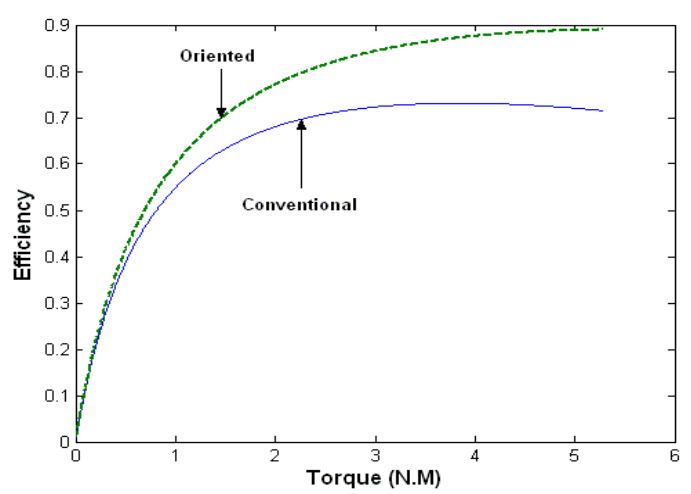

Fig. 18 Variation of efficiency with rotor speed

\section{Third Case of Study}

The run-up characteristics of induction motor for constant flux region and in field weakening region with FOC and with scalar control are studied here where from simulation it is found that;

Fig.19 shows an improvement occurring on the motor torque when applying the FOC on the motor comparing to scalar control where it is found that:

1. In the constant flux region, the torque is directly proportional to the voltage in both of FOC and the scalar control. While, in the field weakening region, the torque is inversely proportional to frequency in two control methods.

2. With field orientation, the torque becomes better when comparing with scalar torque. This is because the angle between rotor and stator fluxes is $90^{\circ}$ with FOC.

3. The torque per ampere of field orientation is higher than that of scalar control.

Fig. 20 shows an improvement occurring on the stator current when applying the FOC on the induction motor comparing with scalar control where it could be concluded that:

1. In constant flux region, the stator current is directly proportional to the voltage in both of FOC and scalar control.

2. With field orientation the stator current becomes enhanced if compared to scalar control case, because the angle between the phasors of rotor and the stator fluxes with field orientation becomes $90^{\circ}$.

3. In field weakening region, the stator current is inversely proportional to the frequency in both of FOC and scalar control. Also, the stator current with FOC becomes enhanced comparing to scalar control.

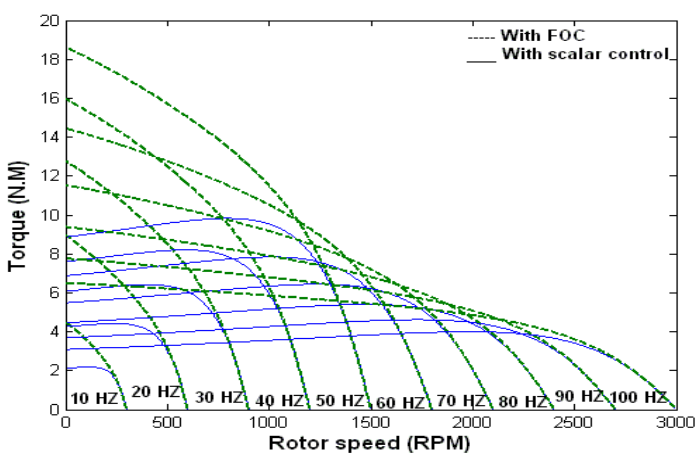

Fig.19 Variation of torque with rotor speed at different frequencies

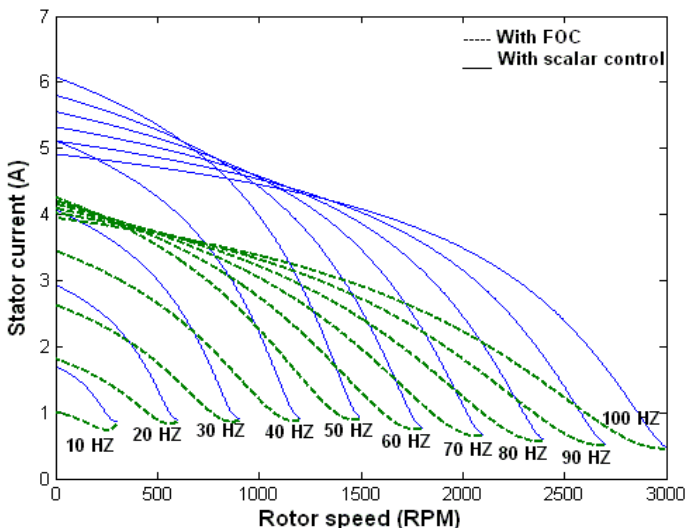

Fig. 20 Variation of stator current with rotor speed at different frequencies

In general, by applying the field orientation, the stator current becomes lower than its values with scalar control.

Fig. 21 shows an improvement occurred on the output power when applying the FOC on the induction motor comparing to the scalar control where it is found that;

1. In the constant flux region, the output power is directly proportional to voltage in both of FOC and scalar control.

2. In the field weakening region, the output power is inversely proportional to frequency in both of FOC and scalar control. In the two regions, the oriented output power as well as oriented torque become improved comparing to scalar output power i.e. with FOC the performance of the motor becomes well. 


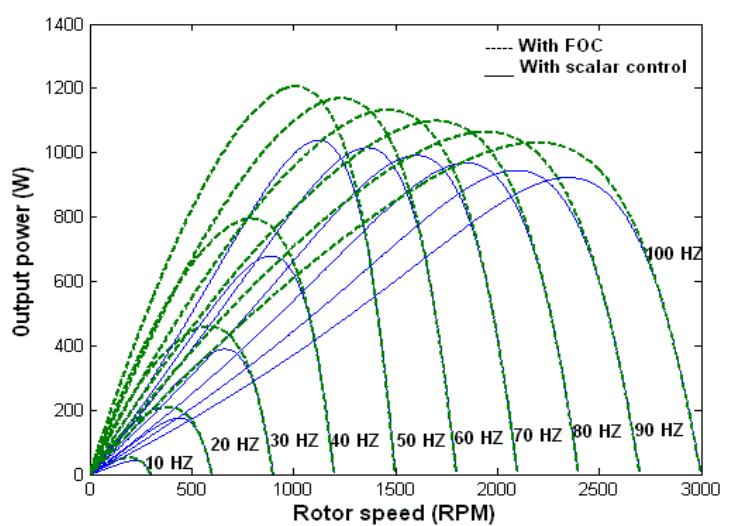

Fig. 21 Variation of output power with rotor speed at different frequencies

Here the effect of frequency variation on the input power in constant flux region and in field weakening region with two control methods is obtained from Fig. 22 and from this Fig. it is found that:

1. In the constant flux region, the input power is directly proportional to voltage in both control methods. While, in the field weakening region, it is inversely proportional to frequency in both of FOC and scalar control.

2 . The input power when applying FOC on motor is less than value when using the scalar control. This is due to the decrease in the oriented stator current when compared with the scalar stator current.

Fig. 23 shows an improvement occurring on the power losses in field orientation comparing with the scalar control where it is found that:

1. In the constant flux region, the power losses are directly proportional to voltage in both of FOC and the scalar control. In field weakening region, the power losses are inversely proportional to frequency in both of FOC and scalar control.

2. The FOC power losses are better than the scalar power losses, because there is a perpendicular between rotor and stator fluxes for each frequency with FOC.

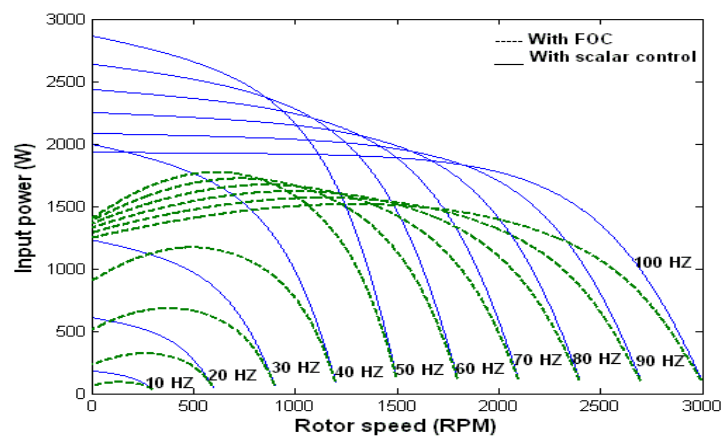

Fig. 22 Variation of input power with rotor speed at different frequencies

Fig. 24 shows an improvement in the efficiency when applying the FOC on the induction motor comparing with scalar control where it is found that:

1. In the constant flux region, the efficiency is directly proportional to the voltage in both of FOC and scalar control while in the field weakening region, the efficiency is still improvement with FOC but it is decreased with scalar control.
2. In field orientation, the efficiency becomes better comparing to the scalar control, because there is a right angle between rotor and stator fluxes, this comes from an increase in oriented output power and a decrease in power loss which increases the efficiency when comparing to the scalar control for each frequency.

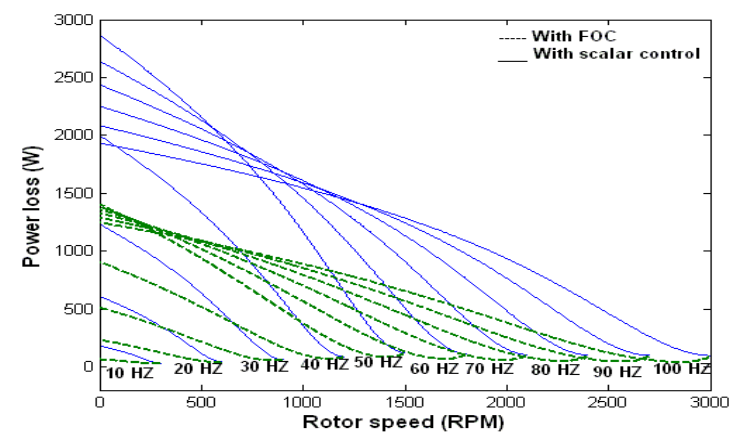

Fig. 23 Variation of power loss with rotor speed at different frequencies

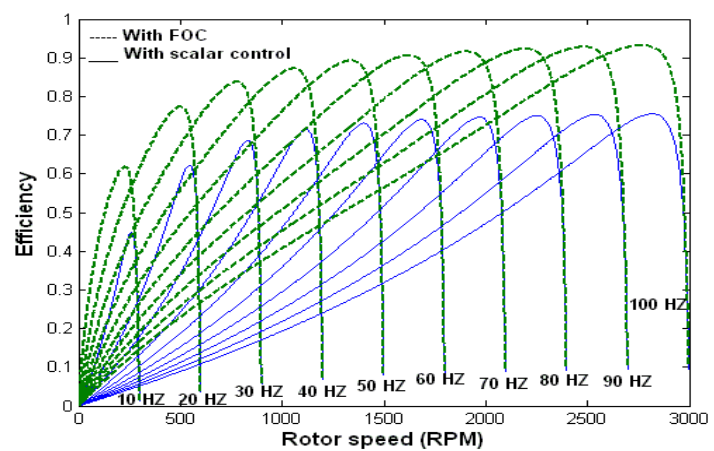

Fig. 24 Variation of efficiency with rotor speed at different frequencies

\section{CONCLUSION}

The main objective of this paper is to compare between the performance characteristics of induction motor with the FOC and with the scalar control. Where it is found that;

1. The induction motor with FOC is better compared to scalar control due to increase in the torque, output power, efficiency and decreasing in the power losses, stator current and input power.

2. When applying the FOC on the induction motor, the parameters are more sensitive if compared with scalar control.

3. At starting, the ratio between the value of oriented starting torque to the conventional starting torque reaches to more than $200 \%$. This is because the angle between the rotor and stator fluxes with conventional method is at its smallest value while in FOC one is still kept constant $90^{\circ}$.

4. At rated power losses the load torque is the rated value with scalar control but with FOC at rated power losses the load torque is higher. This means that, with FOC the motor is up rated without overheating.

5. The torque per ampere with FOC is higher than the torque per ampere with scalar control.

6. In constant flux region, when transmitted from a frequency to another, the variation in the performance characteristics of induction motor are noticeable; this is because these characteristics are directly proportional to the voltage while in field weakening region, effect of this 
transmitted is small because the stator voltage comes to its rated value and frequency increases.

\section{APPENDIX 1}

MOTOR DATA

\begin{tabular}{|l|l|}
\hline Line to line voltages & $380 \mathrm{~V}$ \\
\hline Full load current $\left(\mathrm{I}_{\mathrm{f}}\right)$ & $1.47 \mathrm{~A}$ \\
\hline Rotor speed $\left(\mathrm{n}_{\mathrm{r}}\right)$ & 1400 R.P.M \\
\hline Pole pairs & 2 \\
\hline Full load torque $\left(\mathrm{T}_{\mathrm{f}}\right)$ & $3.82 \mathrm{~N} . \mathrm{m}$ \\
\hline Power factor $(\mathrm{pf})$ & 0.8 \\
\hline Stator resistance & $13 \mathrm{Ohm}$ \\
\hline Stator reactance & $10.5 \mathrm{Ohm}$ \\
\hline Magnetizing reactance & $231 \mathrm{Ohm}$ \\
\hline Rotor resistance & $2.25 \mathrm{~S}+12.35 \mathrm{Ohm}$ \\
\hline Rotor reactance & $-3.694 \mathrm{~S}+19.2643 \mathrm{Ohm}$ \\
\hline Output power & $0.75 \mathrm{hp}$ \\
\hline $\mathrm{T}_{\mathrm{s}} / \mathrm{T}_{\mathrm{f}}$ & 2.33 \\
\hline $\mathrm{T}_{\text {max }} / \mathrm{T}_{\mathrm{f}}$ & 2.62 \\
\hline $\mathrm{I}_{\mathrm{s}} / \mathrm{I}_{\mathrm{f}}$ & 4.22 \\
\hline Efficiency & 0.72 \\
\hline
\end{tabular}

\section{REFERENCES}

[1] M.D. Murphy, F.G Turnball: Power electronic control of A.C motors, Pergamon press, 1986.

[2] Bose B.K: Power Electronics and Variable Frequency Drives, IEEE Press, 1997.

[3] W.B Rosink, "Analogue control system for A.C motor with PWM variable speed," in proceedings of Electronic Components and Application, vol. 3, no. 1, pp. 6-15, May 1980.

[4] B.G. Starr, J.C.F. Van Loon, "LSI circuit for AC motor speed control," in proceedings of Electronic Components and Application, vol. 2, no. 4, pp. 219-229, August 1980.
[5] F. Blaschke, "The Principle of Field Orientation Applied to the New Transvector Closed-Loop Control System for Rotating Field Machines," Siemens-Rev., vol. 39, pp. 217-220, 1972.

[6] Dr.P.S.Bimbhra, Generalized Theory of Electrical Machinery, Romesh Chander Khanna, Delhi-110006 India, 1977.

[7] W. Leonhard, "Field Orientation for Controlling AC Machines Principle and Application," A tutorial, IEE conf. on power electronic variable speed drives conf. pub. No. 291, London, pp. 277-282,1988.

[8] R.Krishnan, F.C. Doran, "Study of parameter sensitivity in high performance and inverter fed Induction motor drive system," IEEE Transactions on Industry Applications. Vol. IA-23 No.4, pp.623-635, 1986.

[9] R. Krishnan, A.S. Bhardawaj, "A Review of Parameter sensitivity and adaptation in Industrial vector controlled Induction motor drive system," IEEE Trans. on Power Electronics, Vol.6, No.4, 1991 pp.219-225, 1991.

[10] Hamid.A. Toliyat, Emil Levi, Mona Raina, "A Review of RFO Induction motor parameter Estimation Technique," IEEE Transaction on Energy Conversions, Vol.18, No.2, pp 356-365, 2003.

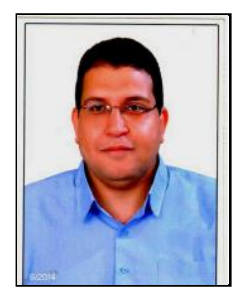

Dr. Hamdy Mohamed Soliman was born in Cairo-Egypt on $26^{\text {th }}$ December 1970 , He received B. Sc. in Electrical Power and Machine Engineering from Helwan University in 1993 and $\mathrm{PhD}$ Degree from Cairo University, Giza, Egypt in 2016.He is a director of development and research of train units in Egyptian company metro. His current research interests include motor control and drive systems. 